\title{
Teaching Method of Folk Music Appreciation in the Music Appreciation Course for International Students in China
}

\author{
Wang Qing \\ North China University of Water Resources and Electric Power, Zhengzhou, Henan, China
}

Keywords: Teaching Method, Folk Music, Appreciation

Abstract: North China University of Water Conservancy and Hydropower has resumed the recruitment of international students since 2016. There are currently 370 enrolled students, including 295 undergraduates, 55 masters, and 20 doctors. There are 29 graduates. According to the number of registered foreign students in the province, the school is now ranked fourth in the province. The countries of origin for enrolled international students are mainly Morocco, Pakistan, Uzbekistan, Kyrgyzstan, Russia, Zambia, Bangladesh, Zimbabwe, Tanzania, Ethiopia, Indonesia, Belarus, Peru, Mongolia, Ukraine and other 23 "Belt and Road" routes nation. The author mainly used the three well-known musical instruments of Hulusi, Guzheng and Erhu to enter the classroom of international students as examples: in the 2020 autumn semester "China Overview" course, 2 hours of folk music appreciation related content was opened for international students; in the spring semester of 2021 The business Chinese major "Music Appreciation" offers 4 hours of folk music appreciation.

\section{The current situation of music appreciation class in the teaching of North China Water Conservancy and Hydroelectricity undergraduate international students in China}

North China University of Water Conservancy and Hydropower has resumed the recruitment of international students since 2016. There are currently 370 enrolled students, including 295 undergraduates, 55 masters, and 20 doctors. There are 29 graduates. According to the number of registered foreign students in the province, the school is now ranked fourth in the province. The countries of origin for enrolled international students are mainly Morocco, Pakistan, Uzbekistan, Kyrgyzstan, Russia, Zambia, Bangladesh, Zimbabwe, Tanzania, Ethiopia, Indonesia, Belarus, Peru, Mongolia, Ukraine and other 23 "Belt and Road" routes nation. At present, the undergraduate majors that the school is open to international students include: mechanical engineering, civil engineering, international economics and trade, and business Chinese.

Since the resumption of international student enrollment in 2016, the author has been responsible for the teaching management of international students and participated in the formulation of four undergraduate professional training programs for international students. From the comparison of the four major training programs, the chapter introducing the charm of traditional Chinese art in the "China Survey" course in the public basic courses involves ancient Chinese music and art, and the 
business Chinese major offers a separate quality elective course. Course of "Music Appreciation". North China University of Water Conservancy and Hydropower is the lead unit of Chinese universities in the "BRICS Network University" identified by the Ministry of Education. The "Music Appreciation" course for Chinese students of this school is one of the compulsory courses in the public art curriculum. The school attaches great importance to cultivating students' aesthetic education, Established the Humanities and Arts Education Center in 2002. Aiming at the characteristics of college students, we put aesthetic education and knowledge transfer in activities that young students love to see and enthusiastically participate in, and carry out healthy, beneficial and colorful cultural and artistic activities to enhance students' aesthetic experience and cultivate students' appreciation of beauty and creativity The ability of beauty has enriched and enriched the students' amateur cultural life, optimized the education environment, and laid a good foundation for comprehensively improving the cultural quality of students.

\section{Classroom observation results of folk music appreciation and teaching effects}

The author mainly used the three well-known musical instruments of Hulusi, Guzheng and Erhu to enter the classroom of international students as examples: in the 2020 autumn semester "China Overview" course, 2 hours of folk music appreciation related content was opened for international students; in the spring semester of 2021 The business Chinese major "Music Appreciation" offers 4 hours of folk music appreciation. The cucurbit, guzheng, and erhu will be played, interacted, questioned and discussed on the spot, so that international students can feel the charm of Chinese musical instruments, become interested and want to learn. The contents of specific courses are as follows:

The first course is 2 class hours, and the main experiment is Minle as a small teaching group in the "China Survey" course, and 10 students with good Chinese skills from 4 undergraduate majors are selected as the survey objects. The main content of the class is the classification of Chinese musical instruments: percussion instruments, plucked instruments, stringed instruments, and wind instruments. In the introduction to the classification of musical instruments, mainly take the musical instruments used in the national orchestra as an example. The classification of percussion instruments includes big drums, gongs, cymbals, and chimes; plucked instruments such as zheng, yangqin, and pipa; stringed instruments such as erhu; wind instruments such as cucurbit flute and erhu. During the teaching process, the method of displaying pictures is used to let the international students understand the shapes of these musical instruments, and use the multimedia to play the instrumental music such as "High Mountain Flowing Water", "Rice Blind Date", "Two Springs Yinyue" and so on, so that the foreign students can learn from both visual and auditory aspects. Come experience the beauty of Chinese folk music.

In conclusion, the "China Survey" course offered a two-hour folk music appreciation survey for international students. The results show that international students do not have a thorough understanding of Chinese folk music, but only one-sidedly appreciate the timbre of some related musical instruments, and have not fully thought about Chinese folk music. To learn more about the interest.

For the second course, 4 hours, a separate music appreciation teaching group for folk music appreciation will be set up, with 12 offline business Chinese as the main survey subjects, and online 2020 freshmen with 20 undergraduates in 4 majors as supplementary. The main content of the class: First, a brief introduction to the origin, shape, and tone of cucurbit silk, introduction of the creative background of "Phoenix-tailed Bamboo under the Moonlight", live music performed by folk band students of North China University of Water Conservancy and Hydropower; second, a brief description of the origin of Guzheng, The shape, tone, and performance of the introduction to the 
composition of the song "High Mountain and Flowing Water"; the third is to briefly describe the origin, shape and tone of the erhu, and to introduce the background and performance of the creation of the song "The Second Spring Reflected in the Moon"; the fourth is to introduce 12 offline students and folk bands The 3 Chinese students in the performance communicated and tried to play simple notes, and the online international students briefly introduced the national musical instruments of their country; the fifth is offline practice, performing on the same stage with Mr. Wang Jian, the inheritor of the intangible cultural heritage of the Yellow River mud xun , Feel the charm of the Yellow River mud xun on the spot.

In summary, a separate music appreciation course teaching group for folk music appreciation and analysis is set up. After studying the music appreciation course system and simple learning of music theory, it focuses on aesthetics, comprehensively learns relevant knowledge points, highlights local characteristics, and integrates international students. The actual situation, practice and theory are combined to avoid boring teaching methods, so that international students can intuitively feel the sound principle and the beauty of musical instruments. From the observation of the classroom, students are more interested. The shortcomings, due to the language and the lack of bilingual music appreciation materials (English and Chinese), bilingual teaching has higher teaching requirements for teachers, and sometimes there are big differences in the translation of national musical instruments, which causes obstacles to the understanding of foreign students.

\section{Analysis of the results of the questionnaire survey on the teaching of folk music appreciation}

There are 47 international student workers who participated in the questionnaire. These 47 are undergraduate international students enrolled in North China University of Water Conservancy and Hydropower in the fall of 2020 and the Spring Festival of 2021. Among them, 38 are from Morocco and 3 are from Pakistan and Uzbekistan. 1 person, 1 person from Russia, 2 people from Peru, 1 person from Ethiopia, 1 person from Zambia. The undergraduate international students of these two grades have already taught a course on China Overview. Among them, 10 of them majored in Business Chinese have offered a music appreciation course in the first semester. The survey results are as follows:

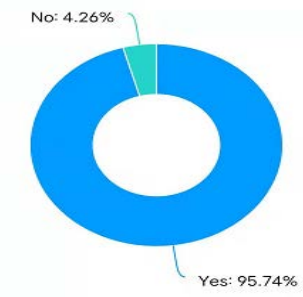

Figure 1 Are you interested in Chinese music?

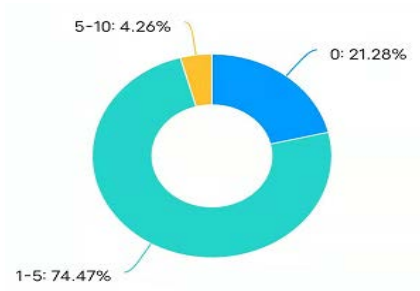

Figure 2 How much do you know about Chinese musical instruments? 


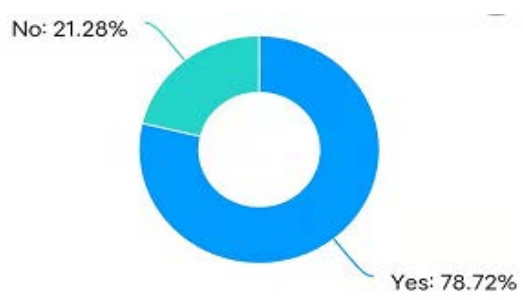

Figure 3 Do you like Chinese opera music

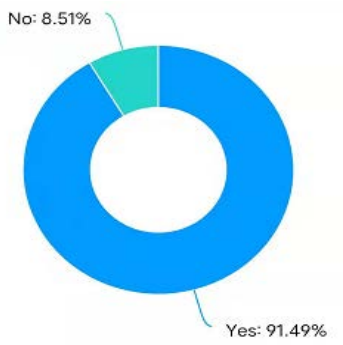

Figure 4 Do you want to offer a separate course on Chinese folk music appreciation

As can be seen from the above data, among the 47 undergraduate international students in China, 95.74\% of them are interested in Chinese music, and $91.49 \%$ of them want to offer a separate course on Chinese folk music appreciation. Opera music has a certain degree of difficulty in singing and performance, and it requires a certain degree of cultural accumulation to understand the music image in it. The degree of foreign students' love of opera music is slightly lower. It can be seen from Figure 2 that $74.47 \%$ of Chinese musical instruments have an understanding of 1-5 kinds of musical instruments. It can be seen that it is advisable to add some small musical instrument learning and musical instrument appreciation content to the folk music appreciation course. Observations in the classroom are also sufficient to illustrate this point. International students have very high learning expectations for Hulusi and Xun.

To sum up, in the quality elective courses of the undergraduate training program for international students in China, a separate folk music appreciation course of 32 hours can be offered, including 8 hours of course practice, and the practical course can be used as a separate small musical instrument learning time. Through the study of folk music appreciation courses, international students in China can master the knowledge of Chinese folk music modes and the basic theoretical knowledge of music; master the music expression forms and music genres of different works in various periods in China; understanding; The musical emotions that the folk music works need to express, so as to improve the imagination of the foreign students in China; understand the outstanding music works of different styles of Chinese folk music, and broaden the music horizon.

\section{References}

[1] Zhao Yue. Analysis of the Teaching Method of Listening to Chinese Songs and Learning Chinese in Teaching Chinese as a Foreign Language [J]. Exam Weekly. 2010.

[2] Mai Qiong. The difference between Chinese and Western music aesthetics [J]. Journal of Nanjing University of the Arts, 2002.

[3] Wei Shuang. On the application of music and film in teaching Chinese as a foreign language[J]. Talent, 2012.

[4] Zhou Junli. Application of Chinese Songs in International Chinese Classroom Teaching [D]. Master's Degree Thesis, Chongqing Normal University. 2016. 